\title{
PELAS MULHERES INDÍGENAS: UM PANORAMA DAS TRAJETÓRIAS FEMININAS INDÍGENAS
}

\author{
SUZELI SANTOS SANTANA (UESC-BA) ${ }^{1}$
}

\begin{abstract}
RESUMO: O artigo objetiva discutir questões sobre gênero, violência e política a partir das reflexões apontadas por Lagarde (2010) e Valcárcel (2012), mais especificamente, articular relatos de mulheres, presentes no livro Pelas mulheres indígenas (2015), com questões relativas à violência de gênero e à política, visto que muitas são líderes de suas comunidades e participam na luta por demarcação de terras. A publicação é organizada pela ONG Thydêwá e traz relatos e reflexões de mulheres de oito diferentes comunidades indígenas da região Nordeste. Considerando esse segmento duplamente subalternizado na sociedade patriarcal, por seu gênero e raça, o presente trabalho procura também dar visibilidade a essas vozes femininas, indígenas e nordestinas, bem como às suas experiências no âmbito privado e público.
\end{abstract}

PALAVRAS-CHAVE: Mulheres indígenas. Dupla alteridade. Política. Violência de gênero.

ABSTRACT: The present article aims to discuss issues of gender, violence and politics, based on the reflections pointed out by Lagarde (2010) and Valcárcel (2012). In this sense, it is intended to articulate the reports of indigenous women present in the book Pelas mulheres indigenas (2015) on political issues, since many women are leaders of their communities, and are at the forefront of the struggle for demarcation of lands, and issues related to gender violence, given the high incidence of violence in these women's reports. The publication is organized by the NGO Thydêwá, which brings narratives and reflections of women from eight different indigenous communities in the Northeast region. Considering this segment doubly subalternized in patriarchal society, by their gender and their race, the present work also aims to give visibility to indigenous women's voices in the Northeast, and legitimacy to their experiences in the private and public spheres.

KEYWORDS: Indigenous women, Double alterity, Policy, Gender violence.

\section{INTRODUÇÃO}

Nos últimos anos, a discussão em torno da intersecção entre gênero, raça ${ }^{2}$ e classe tem ganhado mais fôlego no meio acadêmico. Mesmo entendendo o feminismo como uma luta pela liberdade de todas as mulheres, independentemente de sua raça, classe, orientação sexual, é preciso reconhecer a urgência em tornar visíveis as demandas de mulheres duplamente subalternizadas pelo seu gênero e sua raça, no caso, negras e indígenas.

Apesar de ainda haver um longo caminho pela igualdade e liberdade do primeiro grupo, é notável o crescimento do movimento feminista negro e a inserção de suas demandas nas diversas esferas sociais. No entanto, não se pode dizer o mesmo sobre as mulheres indígenas. Nesse sentido, o artigo objetiva dar visibilidade às vozes femininas indígenas, mais

\footnotetext{
${ }^{1}$ Mestre em Letras: Linguagens e representações pela Universidade Estadual de Santa Cruz (UESC-BA), email: su.ze.liss@hotmail.com

2 O presente trabalho vale-se do termo "raça" no sentido de estratégia política, pois compreende-se que raça no sentido biológico não existe, mas sim identidades que foram racializadas. Nesse sentido, é preciso lembrar que o termo "indígenas" também é uma categoria racializada, instituída pelo colonizador. No entanto, o uso desses termos constitui uma reapropriação, ou ainda uma ressemantização do que lhe foi imposto para fins subversivos. Para saber mais sobre a questão do uso do termo "raça" como estratégia política, ver: MIGNOLO, Walter D. Desobediência epistêmica: a opção descolonial e o significado de identidade em política. Cadernos de Letras da UFF: Dossiê: Literatura, língua e identidade, n.34, p.287-324, 2008.

Disponível em: <http:://www.uff.br/cadernosdeletrasuff/34/traducao.pdf>. Acesso em: set. 2018.
} 


\title{
$=$ TRAMA $=$
}

especificamente de mulheres de oito comunidades indígenas da região Nordeste (Kariri-Xocó $(A L)$, Pankararu (PE), Pataxó Hãhãhãe (BA), Pataxó de Barra Velha (BA), Pataxó de Dois Irmãos (BA), Tupinambá de Olivença (BA), Xokó (SE), Karapotó Plaki-ô (AL), através de suas narrativas presentes no livro Pelas mulheres indígenas (2015), do qual são autoras e protagonistas.

Nesse sentido, o presente trabalho apresenta um panorama das trajetórias das mulheres indígenas pertencentes às comunidades supracitadas, respeitando as especificidades e complexidades da cultura indígena, os limites do nosso conhecimento sobre a vida destas mulheres e a ideia de não essencializar as experiências femininas, atitude que obviamente inclui as mulheres indígenas. Isto é, o estudo evita o caminho do relativismo cultural e do essencialismo - abordagens combatidas fortemente pelo feminismo - pois se reconhecem as particularidades das culturas indígenas, a autonomia destes povos e a heterogeneidade da constituição feminina.

Pelas mulheres indígenas é um dos resultados do projeto homônimo, idealizado pela ONG Twydêwá, que recebeu o apoio da Secretaria de Políticas para as Mulheres da Bahia e da Secretaria de Políticas para as Mulheres da Presidência da República. Segundo o projeto básico do livro em questão, "as mulheres indígenas agentes [...] são lideranças das comunidades onde moram e atuam, tendo interação direta com mais de 47.000 indígenas, e que durante esta iniciativa de 18 meses [tiveram a pretensão de atingir] 8.000 mulheres indígenas e suas famílias (s/d, p. 1)".

Ao articular projetos ligados aos Direitos Humanos por mais de dez anos, a ONG Twydêwá justifica, em seu projeto, a emergência de desenvolver iniciativas voltadas ao enfrentamento da desigualdade e violência de gênero nas comunidades indígenas assim como o empoderamento destas mulheres. Dessa forma, é ressaltado, no projeto da ONG, que

\begin{abstract}
as mulheres indígenas sofrem mais preconceitos que os homens indígenas, maiores abusos das autoridades públicas, maiores dificuldades no mundo social globalizado e também a violência dentro de suas próprias famílias/comunidades. Ao mesmo tempo, são cada dia mais as lideranças indígenas mulheres (temos destaque na Bahia para os trabalhos de 04 "Cacicas"); mais de 80\% "dos" professores nas aldeias são professoras; a maior parte "dos" indígenas que está cursando estudos terciários são mulheres; existem condições suficientes, tanto pelos "problemas" como pelas "potências" para que as mulheres indígenas venham dar um salto quântico e melhorar sua situação e venham melhorar a vida dentro das comunidades indígenas também. Agora mais do que nunca devemos investir no fortalecimento das mulheres indígenas que já são o portal para uma nova humanidade e que ainda são das "piores vítimas" de nossa sociedade atual (ONG TWYDÊWÁ, s/d, p. 4).
\end{abstract}

Nessa perspectiva, ao se considerar a legítima participação política das mulheres indígenas em suas comunidades e a incidência da violência de gênero nos relatos dessas mulheres, tanto no âmbito privado, quanto no público (questões expostas no decorrer do artigo), busca-se articular estas narrativas femininas com as reflexões teóricas de Valcárcel (2012), em relação à política das mulheres e Lagarde (2010), quanto à violência de gênero.

\section{VIOLÊNCIA DE GÊNERO CONTRA MULHERES INDÍGENAS}

A violência de gênero atinge mulheres de todas as classes, etnias/raças, idades e orientações sexuais. No entanto, é preciso reconhecer que esse fato se processa de forma diferente em mulheres em condições historicamente subalternas, isto é, negras, indígenas, pobres, lésbicas, por se encontrarem em situação de maior vulnerabilidade por sua dupla condição de "Outro", isto é, por estar fora das normas universalizantes e hegemônicas. 


\title{
$=$ TRAMA $=$
}

Nesse contexto, torna-se urgente discutir as relações de poder na tríade gênero-raçaclasse, mais especificamente, discutir a condição das mulheres indígenas, por serem vítimas recorrentes de violência nos espaços públicos e privados, o mesmo ocorrendo devido também a sua classe social, pois grande parte dos povos indígenas vive em condições econômicas desfavoráveis.

Lagarde, em "El derecho humano de las mujeres a una vida libre de violencia" (2010), traz importantes contribuições sobre a violência de gênero. A antropóloga adere à definição de violência contra as mulheres proposta pela Declaração sobre a Eliminação da Violência contra a Mulher, a qual é igualmente adotada neste trabalho:

por violencia contra la mujer se entiende todo acto de violencia basado en la pertinencia al sexo femenino que tenga o pueda tener como resultado un daño o sufrimiento físico, sexual o psicológico para la mujer, así como amenazas a tales actos, la coacción o la privación arbitraria de la libertad, tanto si se producen en la vida pública como en la vida privada (LAGARDE, 2010, p. 478).

Importante destacar que a violência contra a mulher tanto acontece no âmbito público como no privado, o que nos leva a pensar no lema "o pessoal é político", clássico da segunda onda do feminismo nos anos 60. Nesse sentido, observa-se a condição de violência a que as mulheres indígenas nordestinas são submetidas em seus próprios discursos. Araruana Pataxó relata:

\begin{abstract}
Uma vez, conheci um rapaz na porta da escola. Ele ficava assobiando para mim. Depois de certo tempo, eu falei para minha mãe que eu tinha conhecido um rapaz. Minha mãe disse: "Araruana, vai estudar!". Não Ihe escutei e comecei a namorar esse rapaz. Eu estava na quarta série, então, parei de estudar. Minha mãe viu que ele não era da cidade, ficou com pena e colocou ele para morar dentro da nossa casa.

Nessa época, minha mãe estava grávida do meu irmão caçula. Enquanto a parteira fazia o parto da minha mãe, eu perdia a virgindade. Eu consenti. Uma semana depois, ele fugiu de casa e me largou encubada (grávida). Nessa época, as moças não podiam ficar encubadas, elas tinham que casar. Eu tinha 10 anos. Fiquei grávida já nessa primeira relação. Tive meu primeiro filho antes dos 12 anos e o segundo antes dos 13 anos. Depois que tivemos o terceiro filho, ele se tornou violento e começou a me agredir
\end{abstract}

(PATAXÓ, 2015, p. 6, grifos nossos).

$\mathrm{Na}$ primeira parte do relato, observam-se alguns aspectos recorrentes na realidade feminina negra e indígena, considerando que muitas destas mulheres, por estarem em condições sociais e econômicas desfavoráveis, iniciam sua sexualidade precocemente e se submetem a relacionamentos violentos.

Importante destacar também a questão do casamento: assim como na cultura ocidental, os indígenas dessa comunidade também são adeptos a essa "tradição", na qual não se aceitam mulheres grávidas se não forem casadas, fato que leva muitas mulheres a se submeterem a relações abusivas por mera convenção social.

Sobre o rapaz que a engravidou, Araruana não dá maiores informações, mas é provável se tratar de um homem maior de idade, que cometeu um estupro de vulnerável. Tais constatações se baseiam nas práticas patriarcais, nas quais os números de casamentos infantis são alarmantes e a cultura de estupro é preeminente. Essa situação grave ocorre embora o Estatuto da Criança e do Adolescente (ECA), no artigo $2^{\circ}$, considere criança a pessoa até 12 anos de idade incompletos; e o Código Penal Brasileiro, por sua vez, alterado pela Lei № 12.015, de 7 de agosto de 2009, decreta, no Art. 217-A, estupro de vulnerável o ato de "ter conjunção carnal ou praticar outro ato libidinoso com menor de 14 (catorze) anos". 


\section{$=$ TRAMA $=$}

No entanto, como será discutido adiante, os povos indígenas têm autonomia para aderir a estas leis ou seguir suas próprias leis, visto que a Constituição Federal de 1988 reconhece aos indígenas, no Artigo 231, "sua organização social, costumes, línguas, crenças e tradições, e os direitos originários sobre as terras que tradicionalmente ocupam, competindo à União demarcá-las, proteger e fazer respeitar todos os seus bens", e, no Artigo 232, garante que "os índios, suas comunidades e organizações são partes legítimas para ingressar em juízo em defesa de seus direitos e interesses, intervindo o Ministério Público em todos os atos do processo".

De volta ao relato de Araruana, vale destacar que seu parceiro abandona a paternidade e passa a agir violentamente contra ela. Posteriormente, Araruana Pataxó conta sobre sua busca por uma saída da condição de violência:

Fiz uma denúncia na polícia. Eles aconselharam minha mãe a arrumar um dinheiro para eu ir embora. Deixei meus filhos com minha mãe e fui embora para Vitória, mas ele sempre conseguia me achar e pedia perdão, dizia que não iria fazer mais aquilo. Eu o perdoava por causa dos meus filhos. Fui embora para Vitória umas quatro vezes e, todas as vezes, ele me achava e falava que não iria fazer mais aquilo.

Em uma dessas vezes, ele me bateu e a cada pancada ele me tirava um dente. Um dia ele pegou uma faca de mesa e enfiou a metade na minha costela. Ele também feriu minhas partes íntimas... Até hoje, lembro-me do mal que ele me fez (PATAXÓ, 2010, p. 6).

Nessa passagem, faz-se pertinente observar a ineficácia da polícia no combate à violência contra mulher, o que leva muitas mulheres a continuarem em relações abusivas pelo fato de não terem alternativas. A questão da maternidade também é um ponto de discussão importante, pois muitas ainda mantêm vínculos com seus parceiros/agressores, pensando serem incapazes de sustentar seus filhos sozinhas, algo comparável à mística circunscrita em ser mulher-mãe, aspecto discutido por Alicia H. Puleo:

La mística de la mujer-madre encubre la realidad de que las mujeres que renuncian a todo por la maternidad y el matrimonio son justamente las que más decepcionadas y tiránicas se muestran después. El altruismo que se predica a las mujeres es impracticable, ya que implica la negación del propio yo. El amor no puede ser identificado con este sacrificio sin pervertirse. La mujer exige la seguridad a cambio de su auto-negación en el matrimonio. Pero, entonces, realiza un comercio, no un sacrificio. Incluso peor, se trataría de un engaño porque nunca ha tenido un yo propio. Esta será la situación, señala la autora [Hélène Deutsch], mientras la subsistencia de la mujer dependa del matrimonio (2010, p. 55).

A recorrência de atos violentos, que vão da violência psicológica até a violência física, é explícita no relato de Araruana. Em seguida, ela narra sua segunda tentativa de fuga dessa realidade agressiva à qual estava submetida:

Quando eu tinha 17 anos, minha mãe juntou um dinheiro e eu pude viajar para o Rio de Janeiro. Lá, não conhecia ninguém. Perto da rodoviária, tinha um viaduto, onde os mendigos viviam. Dormia em uma caixa de papelão, entre dois mendigos que cuidavam de mim. Com nojo de comer resto de comida, fiquei 22 dias sem comer. Desmaiei de fome e acordei no hospital. O filho do gerente do hospital me deu banho e perguntou minha história. Ele falou que eu só sairia dali depois que arrumasse um canto para ficar e um emprego. Como eu estava assustada, fugi do hospital. Fui parar na mesma ponte e novamente passei mal e fui levada ao mesmo hospital. Dessa vez, o gerente me vigiou e só saí para trabalhar na casa de uma família que cuidou de mim e me ajudou muito.

Tive a oportunidade de voltar à minha aldeia. Conheci um índio que é um homem maravilhoso. Hoje, sou casada com ele. Quero deixar um recado para as 


\section{$=$ TRAMA $=$}

mulheres: Não se deixe ser agredida por seu marido. Denuncie, hoje temos a lei Maria da Penha! (PATAXÓ, 2015 p. 6, grifos nossos).

A parte final do relato de Araruana revela a importância de se interseccionar não somente os fatores gênero e raça como também os de classe social. Araruana, nesse sentido, é desumanizada pelo sistema capitalista, mas principalmente por ser mulher, pela violência de gênero que sofreu e a impulsionou a se submeter a outras cruéis situações. Sob esse viés de inferiorização do "Outro", Fernandes (2016), a partir do pensamento de Immanuel Wallerstein (1997), aponta que "a desvalorização do Outro que não conduz à morte, mas a um quadro permanente de inferioridade, é a base do sistema capitalista, pois assegura a exploração do sujeito considerado de segunda classe" (FERNANDES, 2016, p. 692-693). Apesar de esta reflexão se dirigir especificamente à intersecção entre gênero e raça, cabe estender a discussão às questões de classes sociais, visto que o sujeito de classe baixa também constitui o "Outro", o segundo dos pares.

Nessa perspectiva, Lagarde (2010, p. 478) ressalta que as situações sociais de maior igualdade de gênero e menores índices de violência acontecem em países nos quais a democracia igualitária se articula com o desenvolvimento social equitativo e a qualidade de vida. Dessa forma, é preciso reconhecer o atravessamento de outras lutas na luta pelos direitos das mulheres, como a de classes e igualdade racial.

Araruana Pataxó termina seu relato incentivando as mulheres a denunciarem seus agressores ao informar sobre a Lei Maria da Penha. Apesar de reconhecer que a Lei supracitada constitui uma grande vitória das mulheres, a sua efetivação ainda apresenta grandes déficits, visto que muitas mulheres denunciantes se encontram em situação de vulnerabilidade e não recebem a assistência da qual precisam, ficando novamente reféns de seus agressores. Ademais, existem lacunas no texto legislativo; prova disso é o fato de a lei especificar que apenas a violência doméstica e familiar contra mulher será coibida e prevenida, quando se sabe que a violência de gênero deve ser enfrentada igualmente no âmbito público.

Importante acrescentar, no entanto, que o maior desafio da aplicação da Lei Maria da Penha nas comunidades indígenas é a sua autonomia como um direito constitucional, pois isto torna a lei facultativa nestes grupos sociais. Contudo, o artigo $2^{\circ}$ garante a todas as mulheres o direito de viver sem violência:

Toda mulher, independentemente de classe, raça, etnia, orientação sexual, renda, cultura, nível educacional, idade e religião, goza dos direitos fundamentais inerentes à pessoa humana, sendo-lhe asseguradas as oportunidades e facilidades para viver sem violência, preservar sua saúde física e mental e seu aperfeiçoamento moral, intelectual e social (BRASIL, 2006, p. 1).

Verdum (2008, p. 8) salienta, em "Mulheres indígenas, direitos e políticas públicas", a complexidade em abordar as questões de violência e discriminação contra as mulheres indígenas, assim como em propor encaminhamentos adequados para tais situações, considerando a perspectiva multicultural, na qual o direito autônomo dos indígenas deve ser reconhecido e respeitado. Sob tal perspectiva, apresenta-se o posicionamento da professora Segato (2003), que assessorou a criação e implementação da Oficina de Capacitação e Discussão sobre Direitos Humanos, Gênero e Políticas Públicas para Mulheres Indígenas, realizada em 2002:

O direito das mulheres dos povos indígenas é, portanto, uma área de dificuldades múltiplas. Depois de iniciado o período de contato intenso com a sociedade nacional, a mulher indígena padece todos os problemas e desvantagens da mulher brasileira, mais um: o mandato inapelável e inegociável de lealdade ao 


\section{$=$ TRAMA $=$}

povo a que pertence, pelo caráter vulnerável desse povo. Se elas reclamam seus direitos baseados na ordem individualista, elas parecem ameaçar a permanência dos direitos coletivos nos quais se assenta o direito comunitário à terra e à divisão do trabalho tradicional na unidade doméstica como base da sobrevivência. Isso torna frágil a sua vontade e legitimidade na reclamação de direitos individuais, que são, por definição e natureza, "universais", e cujos pleitos dirigem-se aos foros de direito estatal e de direito internacional, ultrapassando a jurisprudência tradicional do grupo étnico (SEGATO, 2003, p. 31 apud VERDUM, 2008, p. 13).

Observa-se, portanto, a dupla alteridade da mulher indígena, que precisa lutar pelos seus direitos enquanto mulher, sem descentralizar o movimento pelos direitos do seu povo, questão esta discutida por Castilho no artigo "A violência doméstica contra a mulher no âmbito dos povos indígenas: qual lei aplicar?", no qual trata de medidas adequadas para o enfrentamento da violência de gênero nas comunidades indígenas, sem deixar de respeitar a cultura autônoma indígena, e como a Lei Maria da Penha é aplicada em favor destas mulheres.

Apesar da dificuldade da entrada e atuação da Lei Maria da Penha, percebe-se uma mudança nesse paradigma, ilustrado no livro Pelas mulheres indígenas. Além dos relatos das mulheres, o livro ainda conta com uma cartilha, no qual se aborda a violência contra a mulher, e informações sobre medidas protetivas. Nas páginas seguintes, por exemplo, são apresentados os tipos de violência de gênero, exemplificados com depoimentos anônimos de mulheres indígenas.

Nesse sentido, nota-se, ainda que timidamente, a presença e intervenção do feminismo nas comunidades indígenas nordestinas. O engajamento destas mulheres e o conhecimento da Lei Maria da Penha são perceptíveis em toda a cartilha. O livro traz dados estatísticos da violência contra mulher e discursos que encorajam outras indígenas a denunciarem tais situações de desrespeito.

Além de apontar a necessidade de articular as questões de gênero às de raça e etnia, a lei Maria da Penha ainda destaca, no capítulo I do título III, que os profissionais, responsáveis pela efetivação das medidas protetivas, devem ser capacitados nessas questões para o melhor atendimento das mulheres. No entanto, observa-se, nos relatos das indígenas, a negligência policial no atendimento destas mulheres em situação de vulnerabilidade, assim como a violência policial:

Foi uma coisa muito horrível para as mulheres indígenas... Houve muito estupro, até de índias grávidas e de mulheres em resguardo. Os policiais usaram elas. Judiaram delas. As nossas mulher foram muito humilhadas. Amarraram seus maridos perto delas enquanto eram usadas. Tem mulher que ainda hoje se sente envergonhada. Nós, mulheres, somos muito sofridas. Ainda hoje passa muito essa coisa de estupro. Foi lá que começou essa violência que ainda existe contra nós, mulher indígena. Quando a polícia chega nas nossas áreas é com muita agressão, agressão contra as mulheres e contra as crianças também. Agressão verbal e física. Na nossa comunidade, mulheres e crianças também lutam para defender nosso território. Nós, mulher, bota o maracá e a borduna na mão e enfrenta o que for (BRAZ, 2015, p. 14, grifos do autor).

Na seção "Homens e mulheres são diferentes, mas os direitos são iguais", as autoras do livro retomam a discussão sobre a violência de gênero, empoderando as mulheres a identificarem situações de violência, e a não se submeterem a tais condições, por meio da denúncia de seus agressores. Apesar das mulheres indígenas reconhecerem o fato de a Lei Maria da Penha não ter sido propriamente dirigida a elas, e de algumas comunidades terem suas próprias leis, curiosamente, elas ainda se sentem amparadas por tal lei: 


\title{
$=$ TRAMA $=$
}

Nós, mulheres indígenas, não participamos da elaboração da Lei Maria da Penha e, por isso, não há um olhar específico para a nossa cultura. No entanto, estamos protegidas por esta Lei contra a violência doméstica. Em muitas comunidades, existem leis internas, para se resolver estes tipos de situações que precisam ser respeitadas pela sociedade não indígena, já que a Constituição Federal de 1988 garante nossa organização interna.

Nossas leis internas devem ser valorizadas, mas existem problemas que foram introduzidos em nossas aldeias, como o álcool e a droga que nos levam a precisar de ajuda externa.

Existem povos em que, quando um indígena comete violência doméstica, esse índio agressor é retirado da aldeia para que passe um tempo prestando serviço para outra comunidade (ONG TWYDÊWÁ, 2015, p. 38).

Nessa conjuntura, é preciso reconhecer que, embora haja falhas na aplicação da Lei Maria da Penha, sobretudo no que se refere às mulheres indígenas, o discurso feminino na obra em questão afirma a importância da lei nas suas comunidades, desmistificando também a ideia de que o conhecimento sobre este instrumento legal não chega nesses espaços.

\section{PELAS MULHERES INDÍGENAS: LUTA E RESISTÊNCIA}

Em La política de las mujeres, Valcárcel (2012) traz importantes discussões sobre a participação das mulheres na política, retomando discussões filosóficas sobre cidadania, liberdade e igualdade. A autora destaca a presença do feminismo no contexto iluminista, ressaltando que a reivindicação de igualdade entre os sexos surge nessa conjuntura. Sobre a divisão entre os sexos, destaca-se o pensamento de Rousseau, um dos principais filósofos do lluminismo, o qual pensava que a divisão entre os sexos não pertencia à ordem do político:

\begin{abstract}
Pues bien, en lo relativo al sexo fue extraordinariamente concluyente: Político es aquello que surge del pacto social; la desigualdad entre los sexos no tiene ese origen; es, por el contrario, natural. El campo social mismo cuando se articula políticamente ha de hacerlo bajo la metáfora de un pacto de todos y dentro del cual producirán todos los pactos necesarios: en orden a las leyes, a la formación de mayorías, las creencias, etc. [...] Las mujeres son la parte de la naturaleza que está introducida en la vida espiritual (que es la política), y deben ser a ella reconducidas si intentan salirse. Porque si se salen se producirá un desorden generalizado en lo político (VALCÁRCEL, 2012, p. 57).
\end{abstract}

Nessa perspectiva, Rousseau coloca as mulheres no plano do natural e os homens no plano do político, naturalizando a hierarquia de poder dos homens sobre as mulheres, isto é, a desigualdade entre os sexos. Apesar de Rousseau ser considerado um teórico da igualdade, ele a restringe apenas aos homens:

La política pertenece a los varones al igual que les pertenece la racionalidad, la jerarquía, la cultura, el temple, el valor, el carácter y la capacidad de acuerdo. Las mujeres deben estar excluidas de la política, limitarse al buen arreglo de su casa, la obediencia, la dulzura y en general a facilitar la libertad y el éxito de los varones a cuya autoridad han sido subordinadas (VALCÁRCEL, 2012, p. 77-78).

No entanto, Valcárcel ressalta que Woolstonecraft, filósofa e defensora dos direitos das mulheres, rebate o sexismo de Rousseau, questionando a ideia da natural hierarquia dos sexos, em que o homem se sobrepõe à mulher. Dessa forma, Valcárcel (2012, p. 60) conclui que, se a igualdade política é atribuída a alguns em função de seu sexo, havia que declarar natural a desigualdade que se instaurava. Esse naturalismo, segundo a autora, era sustentando pelo essencialismo: 


\section{$=$ TRAMA $=$}

Sí sólo se concede igualdad en función de un único parámetro y este parámetro es la pertenencia al sexo masculino, y de ahí entonces advienen la ciudadanía y la igualdad política, hay que explicar qué tiene de particular el sexo excluido. El sexo femenino comienza a ser "el otro", el "algo otro". Ese "otro" del que se afirma la continuidad con la naturaleza. Pero para todo ello hay que esencializar, es decir, hay que comenzar a explicar y definir a "la mujer" como algo distinto de lo humano en general. El naturalismo tiene que deducir una esencia, no le queda más remedio que hacer esencia. Y llega tan lejos esta manía de caracterizar qué sea o en qué consista "lo mujer" que acaba por romper con la propia continuidad de la especie dentro de sí (VALCÁRCEL, 2012, p. 60-61).

Nesse sentido, as mulheres são essencializadas e colocadas na condição do "outro", do segundo dos pares. A autora ainda coloca em questão que, se ser igual aos homens significa ter plenos direitos, as mulheres também querem ser como os homens, ter o direito de gozar da liberdade, da dignidade política e ter acesso aos seus bens.

No capítulo IV do livro La política de las mujeres, Valcárcel ainda discute a ausência de modelos de mulheres nos espaços públicos, que se deve simplesmente ao fato de não terem permitido às mulheres ocuparem esses lugares. Assim, a autora fala da necessidade de recuperar a memória de grandes mulheres na história, na política, na ciência, nas artes:

Las mujeres se sienten recién llegadas a los espacios públicos porque en efecto nunca se les ha permitido ocuparlos, pero, sobre todo, porque no suelen conocer ni por tanto reconocer la deuda que con sus acciones colectivas tienen esos espacios. Con gran parte de la historia hurtada, sentimos confusamente que no somos herederas legítimas de ese mundo [...] (VALCÁRCEL, 2012, p. 83).

No entanto, a luta feminista propiciou mudanças nesse paradigma, e as mulheres passam a ocupar os espaços que antes Ihes foram negados. Nessa perspectiva, as mulheres indígenas também têm reivindicado seus direitos, tornando-se agentes sociais e políticas nas suas comunidades, como pode ser visto em muitos relatos no livro Pelas mulheres indígenas.

Nos relatos estudados, observa-se a participação contundente das mulheres nas lutas por demarcação de terra e a atuação política feminina na liderança de suas comunidades. No relato de Arian Pataxó, percebe-se como a luta é inerente à vida destas mulheres:

Eu comecei minha luta indígena quando era criança. Meus pais também são indígenas e me criaram onde vivemos até hoje - Aldeia de Cumuruxatiba.

[...] Apesar de gostar muito de estudar, com apenas dez anos de idade comecei a trabalhar de babá. Até aí eu não tinha conhecimento dos meus direitos como indígena. Minha mãe falava do "fogo de 51". Ouvindo minha mãe, comecei a entender nossa história e, em 2002, entrei na luta pela nossa terra.

Passei por muitas dificuldades quando comecei a lutar. Meu esposo não entendia a minha luta. Não entendia porque eu viajava tanto. Tive que escolher e escolhi a luta. Graças a essa luta, hoje há várias aldeias que ajudei a construir. Uma delas é a Aldeia Dois Irmãos, da qual sou cacica (PATAXÓ, 2015, p. 24).

É de fundamental importância destacar a presença de modelos de mulheres nos espaços públicos, visto que muitas cacicas se tornam referências de força, liderança, autonomia, diferentemente do que fora instituído antes. Nesse sentido, a figura feminina passa a ocupar espaços que antes foram delimitados apenas aos homens e rompe com a ideia rousseauniana de que a mulher pertencia somente ao âmbito doméstico. Quitéria Pankararu foi uma dessas mulheres modelos. Segue o relato de sua filha, que a descreve como um símbolo de luta e resistência:

Falar de minha mãe sempre será emocionante, pois me lembro que, desde sempre, eu a via trabalhando na roça, fazendo vassouras e colhendo frutos para 


\section{$=$ TRAMA $=$}

vender nas feiras. Sempre vi a vontade dela de lutar por nossas terras e por nossos direitos como indígenas.

Várias vezes fui com ela até Recife, Brasília, em vários encontros de lideranças. Nessas viagens, pude ver o quanto ela era respeitada. O nome Quitéria Binga, ou Quitéria Pankararu, sempre teve peso e valor perante outras lideranças.

Ela lutou até seus 82 anos. A grande maioria do povo a amava e a respeitava. Ela conseguiu um posto de saúde que chamamos de maternidade, uma creche onde a maioria de nossos educadores de hoje em dia estudaram ou iniciaram seus trabalhos, e também um tear para produção artesanal de redes de dormir e mantas.

Lembranças boas é o que tenho. Uma guerreira que nunca abaixou a cabeça. Participava ativamente na defesa do nosso território, defendia a saúde e educação voltadas para nossa realidade, respeitando nossos valores sagrados. [...] Mesmo recebendo várias ameaças de morte, tendo até dormido nas serras por conta de posseiros, ela sempre lutou pelas nossas terras e pelo bem-estar do povo. Ela foi um exemplo de luta e resistência! (BARROS, 2015, p. 42).

O relato da cacica Jamopoty Tupinambá é marcante no que concerne ao machismo enfrentado pela mesma ao assumir a liderança de sua comunidade, porque a presença dos homens ainda é predominante na liderança dos povos indígenas. Mas se percebe também no relato de Jamopoty um grande teor de resistência, ao provar que a mulher tinha a mesma capacidade de liderar que o homem:

Meu nome indígena é Jamopoty. Sou mãe, sou avó e, ao mesmo tempo, liderança de um povo. Sou cacique do povo Tupinambá de Olivença. Nós estamos sempre lutando pelos nossos direitos que a Constituição Federal nos garante, mas na realidade do dia a dia nós não temos. Quem sabe o que é bom para nós somos nós. O que o povo Tupinambá quer é seus direitos, quer liberdade.

No início, em 1999, quando fui escolhida por todas as comunidades para ser a Cacique do Povo Tupinambá de Olivença, eu sentia muito o preconceito. Quando eu viajava com outros caciques Pataxó e Pataxó Hãhãhãe, nas reuniões, eles não me davam a palavra.

Depois, fui ganhando a confiança e eles começaram a ouvir minha voz e a me respeitar. Depois disso, eles me ajudaram muito. Tiveram na aldeia e começaram a falar da importância de uma cacica mulher, algo novo para aquela época. Eu percebia que os próprios índios Tupinambá achavam que uma cacica não iria conseguir nada, que não iria aguentar o trabalho. Mas eu mostrei que uma mulher pode sim, que uma mulher pode transformar os pensamentos e tem capacidade de liderar um povo.

Em 2009 fui presa injustamente. Lutar por direitos é ilegal? Fiquei uns dias no presídio feminino e outros três meses em prisão domiciliar. Nós, lideranças indígenas, somos constantemente criminalizadas.

O governo decretou a "garantia da lei e a ordem" para nosso território, supostamente para nos proteger. Já são 11 indígenas assassinados nestes nove meses de 2014 ... E nós só vemos a polícia revistar os indígenas que caminham pelo nosso território, dar baculejo e agredir verbal e fisicamente nossos parentes. Até caso de abuso sexual houve. De apreender as armas dos pistoleiros dos fazendeiros que estão nos matando a gente nunca teve essa notícia. (TUPINAMBÁ, 2015, p. 43).

Apesar de não se exporem todos os relatos de luta das mulheres que fazem parte do livro Pelas mulheres indígenas, é imprescindível ressaltar que, na história da retomada das terras de cada comunidade, as mulheres não assumem meros papéis de coadjuvantes. Pelo contrário, as mulheres são protagonistas da luta e resistência indígena, o que confirma a presença feminina marcante nos espaços políticos, públicos de suas comunidades.

\section{CONSIDERAÇÕES FINAIS}

Diante do exposto, é evidente que o presente trabalho não traçou um panorama histórico das mulheres indígenas, mesmo porque o objeto de estudo - o livro Pelas mulheres 


\section{$=$ TRAMA $=$}

indígenas - é fruto de experiências de mulheres de diversas comunidades indígenas, o que demandaria um trabalho mais extenso. Nesse sentido, o que se propôs foi traçar sinteticamente suas trajetórias, articulando a questão de gênero à de raça, identificando os aspectos de violência e participação política, para dar visibilidade às suas experiências e suas vozes.

A questão da violência, como abordada no primeiro tópico, é incidente na vida das mulheres indígenas. Apesar de elas estarem cientes sobre a Lei Maria da Penha, e algumas comunidades possuírem suas próprias leis, é importante que o Poder Público adeque a lei à realidade das indígenas para que estas possam gozar do direito de uma vida livre, sem violência.

Em síntese, a ONG Twydêwá, com o projeto e o livro Pelas mulheres indígenas, atesta que há uma mudança no paradigma das relações de gênero nas culturas indígenas. Nesse contexto, as mulheres passam a assumir o papel de protagonistas, participam da vida política de suas comunidades, estão adentrando nas universidades, assumindo novos cargos, se engajando, lutando pelos direitos do seu povo, mas também pelos seus direitos, enquanto mulheres.

\section{REFERÊNCIAS}

BARROS, Maria São Pedro. Quitéria Pankaruru. In: ONG TWYDÊWÁ. Pelas mulheres indígenas. [S.I.: s.n.], 2015, p.42. ISBN: 978-85-901957-7-1. Disponível em: <http://www.thydewa.org/wp-

content/uploads/2015/03/pelas-mulheres-indigenas-web.pdf> Acesso em: 10 ago. 2017.

BRASIL. Direitos indígenas na Constituição da República Federativa do Brasil de 1988. Disponível em: < http://portal.mec.gov.br/sesu/arquivos/pdf/leis1.pdf> Acesso em: 24 ago. 2017.

BRASIL. Lei Maria da Penha. Disponível em: <http://www.planalto.gov.br/ccivil_03/_ato2004-

2006/2006/lei//11340.htm> Acesso em: 23 ago. 2017.

BRASIL. Lei № 12.015, de 7 de agosto de 2009. Disponível em:

<http://www.planalto.gov.br/ccivil_03/_ato2007-2010/2009/lei/l12015.htm> Acesso em: 25 ago. 2017.

BRAZ, Maria Rosa. O fogo de 51. In: ONG TWYDÊWÁ. Pelas mulheres indígenas. [S.I.: s.n.], 2015, p. 14-15.

ISBN: 978-85-901957-7-1. Disponível em: <http://www.thydewa.org/wp-content/uploads/2015/03/pelasmulheres-indigenas-web.pdf> Acesso em: 10 ago. 2017.

FERNANDES, Danubia de Andrade. O gênero negro: apontamentos sobre gênero, feminismo e negritude.

Estudos Feministas. Florianópolis, 24(3). 2016, p. 691-713.

KARAPOTÓ PLAKI-Ô, Wilma Yãnami. Reflexões. In: ONG TWYDÊWÁ. Pelas mulheres indígenas. [S.I.: s.n.],

2015, p.26. ISBN: 978-85-901957-7-1. Disponível em: <http://www.thydewa.org/wp-

content/uploads/2015/03/pelas-mulheres-indigenas-web.pdf> Acesso em: 10 ago. 2017.

KARAPOTÓ PLAKI-Ô, Zenaide. Vida renovada. In: ONG TWYDÊWÁ. Pelas mulheres indígenas. [S.I.: s.n.],

2015, p.8. ISBN: 978-85-901957-7-1. Disponível em: <http://www.thydewa.org/wp-

content/uploads/2015/03/pelas-mulheres-indigenas-web.pdf> Acesso em: 10 ago. 2017.

KARIRI-XOCÓ, Itamy; KAYANE, Laura. Atualmente. In: ONG TWYDÊWÁ. Pelas mulheres indígenas. [S.I.:

s.n.], 2015, p. 30. ISBN: 978-85-901957-7-1. Disponível em: <http://www.thydewa.org/wp-

content/uploads/2015/03/pelas-mulheres-indigenas-web.pdf> Acesso em: 10 ago. 2017.

LAGARDE, Marcela. El derechos humano a una vida libre de violencia. In: Virginia Maquieira (Org.). Mujeres, Globalización y Derechos Humanos. Madrid: Cátedra, 2010, p. 477-534.

MIGNOLO, Walter D. Desobediência epistêmica: a opção descolonial e o significado de identidade em política. Cadernos de Letras da UFF: Dossiê: Literatura, língua e identidade, n.34, p.287-324, 2008.

Disponível em: <http:://www.uff.br/cadernosdeletrasuff/34/traducao.pdf>. Acesso em: set. 2017.

ONG TWYDÊWÁ. Pelas mulheres indígenas. [S.I.: s.n.], 2015. ISBN: 978-85-901957-7-1. Disponível em:

<http://www.thydewa.org/wp-content/uploads/2015/03/pelas-mulheres-indigenas-web.pdf> Acesso em: 10 ago. 2017.

ONG TWYDÊWÁ. Pelas mulheres indígenas. [S.I.: s.n.: s.d.] Disponível em:

<http://www.mulheresindigenas.org/wp-content/uploads/2014/02/PROJETO-B\%C3\%81SICO.pdf>Acesso em: 10 ago. 2017.

PATAXÓ, Araruana. Eu consegui. In: ONG TWYDÊWÁ. Pelas mulheres indígenas. [S.I.: s.n.], 2015, p. 6-7. ISBN: 978-85-901957-7-1. Disponível em: <http://www.thydewa.org/wp-content/uploads/2015/03/pelasmulheres-indigenas-web.pdf> Acesso em: 10 ago. 2017.

PATAXÓ, Arian. Por escolha: a luta. In: ONG TWYDÊWÁ. Pelas mulheres indígenas. [S.I.: s.n.], 2015, p. 2425. ISBN: 978-85-901957-7-1. Disponível em: <http://www.thydewa.org/wp-content/uploads/2015/03/pelasmulheres-indigenas-web.pdf> Acesso em: 10 ago. 2017. 
PULEO, Alicia H. Lo personal es político: El surgimento del Feminismo Radial. In: AMORÓS, Celia; MIGUEL, Ana de. (Org.). Teoria Feminista - de la llustración a la Globalización: Del feminismo liberal a la posmodernidad. Vol.2. Madrid: Minerva Ediciones, 2010, p. 35-67.

TUPINAMBÁ, Jamopoty. Liberdade? In: ONG TWYDÊWÁ. Pelas mulheres indígenas. [S.I.: s.n.], 2015, p. 43. ISBN: 978-85-901957-7-1. Disponível em: <http://www.thydewa.org/wp-content/uploads/2015/03/pelasmulheres-indigenas-web.pdf> Acesso em: 10 ago. 2017.

TUPINAMBÁ, Suely. As mulheres "pãe". In: ONG TWYDÊWÁ. Pelas mulheres indígenas. [S.I.: s.n.], 2015, p. 58. ISBN: 978-85-901957-7-1. Disponível em: <http://www.thydewa.org/wp-content/uploads/2015/03/pelasmulheres-indigenas-web.pdf> Acesso em: 10 ago. 2017.

VALCÁRCEL, Amelia. Capítulo III; Capítulo IV. In: La Política de las mujeres. Madrid: Cátedra, 2012, p. 53-87.

VERDUM, Ricardo. Mulheres indígenas, direitos e políticas públicas. In: VERDUM, Ricardo. (Org.). Mulheres Indígenas, Direitos e Políticas Públicas. Brasília: Inesc, 2008, p. 7-19. 